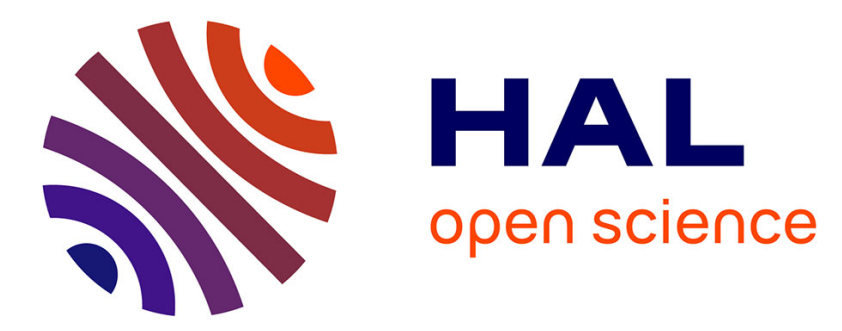

\title{
18th ICPR paper: Realizing block planning concepts in make-and-pack production using MILP modelling and SAP APO
}

Hans-Otto Guenther, Martin Grunow, Ulf Neuhaus

\section{- To cite this version:}

Hans-Otto Guenther, Martin Grunow, Ulf Neuhaus. 18th ICPR paper: Realizing block planning concepts in make-and-pack production using MILP modelling and SAP APO. International Journal of Production Research, 2006, 44 (18-19), pp.3711-3726. 10.1080/00207540600589127 . hal-00512889

\section{HAL Id: hal-00512889 \\ https://hal.science/hal-00512889}

Submitted on 1 Sep 2010

HAL is a multi-disciplinary open access archive for the deposit and dissemination of scientific research documents, whether they are published or not. The documents may come from teaching and research institutions in France or abroad, or from public or private research centers.
L'archive ouverte pluridisciplinaire HAL, est destinée au dépôt et à la diffusion de documents scientifiques de niveau recherche, publiés ou non, émanant des établissements d'enseignement et de recherche français ou étrangers, des laboratoires publics ou privés. 


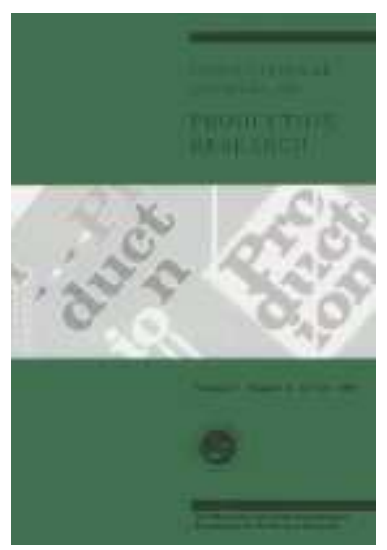

\section{8th ICPR paper: Realizing block planning concepts in make-and-pack production using MILP modelling and SAP APO}

\begin{tabular}{|r|l|}
\hline Journal: & International Journal of Production Research \\
\hline Manuscript ID: & TPRS-2005-IJPR-0454.R1 \\
\hline Manuscript Type: & Original Manuscript \\
\hline Author: & 17-Jan-2006 \\
\hline Complete List of Authors: & $\begin{array}{l}\text { Guenther, Hans-Otto; TU Berlin, Production Management } \\
\text { Grunow, Martin; Technical University of Berlin, Department of } \\
\text { Industrial Management } \\
\text { Neuhaus, Ulf; TU Berlin, Production Management }\end{array}$ \\
\hline Keywords (user): & $\begin{array}{l}\text { PRODUCTION PLANNING, OPERATIONS PLANNING, PROCESS } \\
\text { INDUSTRY }\end{array}$ \\
\hline
\end{tabular}

\section{今 scholaroNE" \\ Manuscript Central}




\title{
Realizing block planning concepts in make-and-pack production using MILP modelling and SAP APO ${ }^{\odot}$
}

\author{
H.-O. Günther†*, M. Grunow $\ddagger$ and U. Neuhaus $\dagger$ \\ $\dagger$ Dept. of Production Management, Technical University of Berlin, Wilmersdorfer Str. 148, \\ 10585 Berlin, Germany \\ \$Dept. of Manufacturing Engineering and Management, Technical University of Denmark, \\ Building 425, 2800 Kgs. Lyngby, Denmark
}

*Corresponding author, email: hans-otto.guenther@tu-berlin.de

\begin{abstract}
In the industrial application environment considered, different variants of a basic product type are produced using the same resources and following the same basic process plan. To support production planning and scheduling for this type of production system, the concept of block planning is introduced, which has gained considerable attention particularly in the consumer goods industry. A block represents a pre-defined sequence of production orders of variable size. In order to demonstrate the practical applicability of the proposed block planning concept, we consider the production system of a major producer of hair dyes as a case study. We present two different implementations of the block planning concept. One utilizes the Production Planning / Detailed Scheduling module of the SAP APO ${ }^{\odot}$ software. The other approach is based on a mixed-integer linear programming formulation. In contrast to the academic literature, a continuous representation of time is chosen. Thus the number of variables and constraints could be considerably reduced. The approach suggested is computationally very efficient and provides the flexibility to model a variety of application specific features.
\end{abstract}

Keywords: Block planning, consumer goods industry, advanced planning systems

\section{Introduction}

In the consumer goods industry, there is often only one single production stage after which final products are packed and shipped to warehouses or individual customers. This type of production environment is known as "make-and-pack production". As a case study the production of hair dyes at a major German producer of consumer goods is considered. Hair dyes as the final product are offered in different colour variants. The composition of each colour variant is defined by bills of material (BOM) which indicate the colour dependent parts 
and materials as well as standard components which do not depend on the specific product variant. Hair dyes are processed on a number of processing and packaging lines which are linked by tanks for intermediate storage. Similar product structures and production systems can be found in many other branches of the consumer goods industry, for example in the production of detergents, cosmetics, fresh food, beverages, and also in the fine-chemicals industry. These branches belong to the process industries (see e.g. Dennis and Meredith 2000) where planners are typically confronted with a variety of constraints, such as limited buffer capacities, products with limited shelf-lives, regulations on hygiene and, in food business, food safety causing considerable cleaning times. Further issues which contribute to the complexity of the detailed production planning and scheduling problems in this industry are increasing product variety, short delivery times and pressure on quality and costs (cf. Honkomp et al. 2000). Basic characteristics of these industries are the following:

- Different variants of a product are achieved by adjusting process parameters, such as process duration, processing mode, and mix of raw materials. Additionally, a variety of packaging formats are available for each product, which leads to a further increase of the number of variants.

- Typically, total demand of the final products is relatively stable, while the allocation of demand among the individual variants differs significantly from period to period. Subject to the predictability of demand and the shelf life of the products, both make-to-stock and make-to-order production strategies can be found.

- Since production is aligned to high output rates, the product routings between the equipment units are fixed and all products pass the units in the same sequence.

- In order to ensure a flexible response to customer demand variations, multiproduct equipment is used. Hence, when changing over between two dissimilar products, cleaning and setup operations are required. Changeover times are often sequence dependent due to the differences in the product and process specifications.

- Most often the production systems employed are highly capital intensive. Hence, high system utilisation levels are required and considerable attention must be given to sequencing and lot sizing decisions.

In the academic literature, only little attention has been paid to production planning and scheduling in the consumer goods industry. Examples of papers dealing with practical applications are van Sonsbeek et al. (1997), van Dam et al. (1998), Mendez und Cerda (2002), Soman et al. (2004), Lütke Entrup et al. (2005). The major part of the papers focussing on the production of multiple product variants on a single production facility have been developed under the assumptions of the classical economic lot scheduling problem (ELSP), which is concerned with generating a cyclical schedule for several products, based on a single resource and constant demand rate (cf. Elmaghraby 1978 and Cooke et al. 2004). However, the assumptions of the ELSP are seldom present in an industrial environment. Therefore related approaches offer only little potential for practical application.

The remainder of this article is organized as follows. In the next section, the concept of block planning, which provides a simple and practical tool for application in the consumer goods industry, is introduced. A basic mixed-integer linear programming model for the block 
planning problem is formulated in section 3. In addition, extensions and alternative objective functions are discussed. In section 4 a brief overview of advanced planning systems (APS) and their capabilities for production planning and scheduling in the consumer goods industry is given. SAP APO ${ }^{\circledR}$ is introduced as an example of APS. Finally the case study of a hair dye production system is investigated in section 5 .

\section{Block planning}

In our paper, a make-and-pack production system is considered in which different types of products are produced using the same type of production equipment. In process industries, there is often a natural sequence in which the various products are to be produced in order to minimize total changeover time, for example from the brighter color of a hair dye to the darker or from the lower taste of a food product to the stronger. Since only a single product can be produced at a time, inventories are to be built up which cover the demand between two successive production runs of the same product. Hence, decisions on the timing and sequence of the production runs, the corresponding lot sizes and inventory levels have to be made.

In order to reduce the complexity of the scheduling problem at hand, we introduce the concept of block planning. A block represents a pre-defined sequence of production orders of variable size, where each production order corresponds to a unique product type. Thus each product type occurs at a given position in each block. Throughout the planning horizon, the production of blocks is repeated in a cyclical fashion, e.g. one block of production orders per week. Depending on the development of demand over time, the size of the individual production order may vary from block to block. Moreover, binary decision variables are used which indicate if a production run for a particular product is scheduled or not. The objective consists of minimizing inventory holding and setup costs while satisfying given customer demands. Major constraints arise from the available production capacities.

In the scientific literature the application of block planning concepts and the development of corresponding optimization models are widely neglected. The related problem of campaign planning, however, has received considerable attention (see e.g. Grunow et al. 2002 and 2003). The major advantage of the block planning concept is that it is easy to implement and it reflects managerial practice prevalent in many make-and-pack production systems.

In rigid block planning, the length of an entire block comprising a given sequence of products corresponds to the length of a so-called macro-period (e.g. a week or a month), while the production quantities for individual products may vary. In flexible block planning, however, as illustrated in figure 1, the start-off and completion times of a block are not directly linked to the period boundaries. Instead, the succession of blocks is based on a temporal repetition sequence and the internal structure of the blocks as well as the length of the corresponding production runs may vary. 


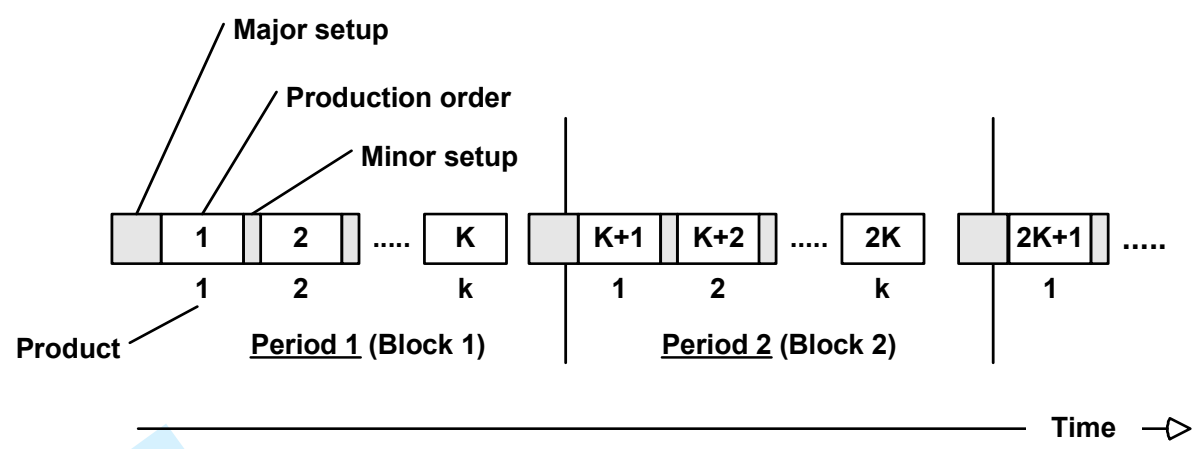

Figure 1: Flexible block planning concept

There are a number of features which characterize the proposed block planning concept. The most important are the following.

- Each block is assigned to a unique period and the execution of the block must be completed before the end of this period.

- In flexible block planning a block is allowed to start in an earlier period as soon as the predecessor block has been completed.

- The composition of the various blocks is not necessarily the same, allowing lowvolume products to be produced only in selected production runs or high-volume products to occur more than once in a block.

- Production orders for certain products may also be skipped in order to save setup times. In this case, demand is satisfied from production orders of the same product in a preceding block.

- For practical reasons, the production sequence within the blocks must be determined in advance, considering sequence dependent changeover costs. In this regard, the definition of blocks is similar to the generation of setup families in discrete parts manufacturing.

- Typically, a major setup operation is performed before starting or after completing a block (e.g. for cleaning the manufacturing equipment), while only a minor setup operation is required when changing between products within the same block (e.g. for provision of material or for adjusting the processing conditions). In many practical applications minor setup times and costs are very small and may thus be neglected.

Today the concept of supply chain management has gained widespread acceptance in industry. Essentially, supply chain management can be regarded as the process of managing transactions and orders between the various stages involved (cf. Chopra and Meindl 2004). Following a pull-oriented view, execution of production activities is initiated in response to a customer request. On the other hand, a push-oriented view is appropriate whenever processes need to be executed in anticipation of customer orders, e.g. in a make-to-stock or a make-toassemble environment. In this case, demand is not known with certainty and must be forecasted. The integration of both views leads to the definition of so-called demand elements, which either represent specific customer orders or forecasts. In block planning, each demand element is linked to a grid point on the time scale and may be filled from initial stock or by production orders, which are assigned to the same or a previous period. As an example, figure 
2 shows three demand elements $d_{k 1}, d_{k 2}$, and $d_{k 3}$ for the same product $k$ assigned to periods 1,2 , and 3 . Figure 2 illustrates the possibility of satisfying these demand elements from initial stock or from a number of production orders $i(k), K+i(k), 2 K+i(k)$, where $i$ indicates the production order of product $k$ within a block and $K$ represents the total number of potential production orders per block. Moreover, the proposed concept of block planning allows the consideration of shelf life by limiting the assignment of demand elements to only the most recent production orders as illustrated in figure 2.

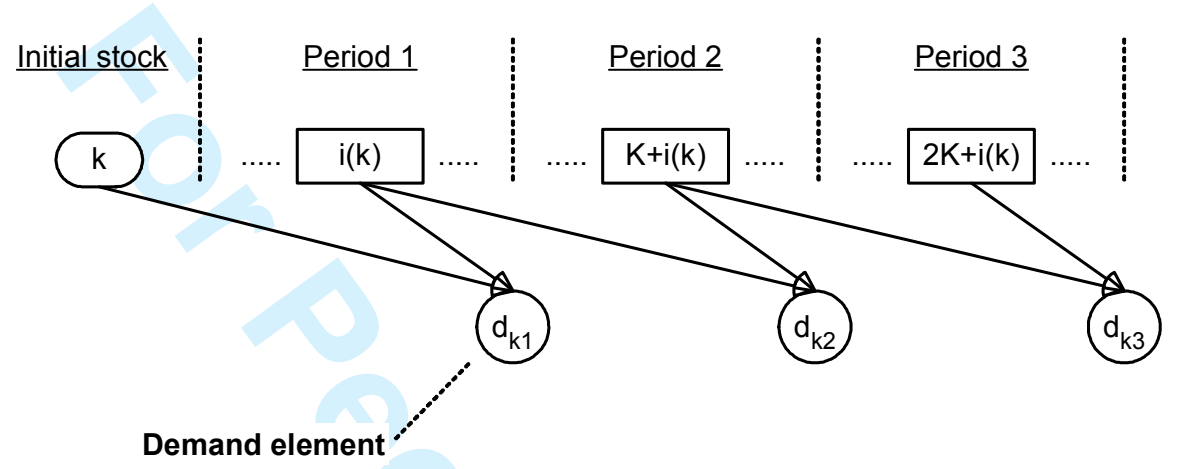

Figure 2: Assignment of demand elements to production orders and initial stock

\section{MILP modelling}

Two different implementations of the block planning concept are proposed. One is based on an MILP model formulation and uses ILOG's OPL Studio as a modelling environment and the standard optimization software CPLEX as solver. The other approach to be presented in section 4 utilizes the modelling capabilities of SAP's APO ${ }^{\circledR}$ (Advanced Planner and Optimizer) software.

\subsection{Basic model formulation}

MILP models for production scheduling can be formulated based on a discrete or continuous representation of time (cf. Floudas and Lin 2004). In the case of a discrete time representation, the planning horizon is divided into smaller periods of equal length, and all material flows as well as start and finish times of the production runs are assigned to the beginning or the end of a period. In order to accurately model the process, the greatest common divisor of all task processing times must be used as the period length. In practice, rounding of processing times is frequently applied in order to decrease the number of periods (and thus the number of decision variables and constraints). The major drawback of rounding up is that the schedule obtained may contain a considerable amount of slack, whereas rounding down may generate infeasible schedules. Another difficulty of this approach is that the number of constraints and binary variables become quite large, especially if a dense time grid is used (cf. Blömer and Günther, 1998 and 2000). 
In this paper we develop an MILP model based on a continuous representation of time. This model formulation offers the advantage of a much more precise consideration of both the timing of the material flows and the production orders. A disadvantage of this modelling technique can be seen in the increased MIP gap, particularly, in the case of extremely largesized problem instances. However, according to our experience, the computational effort required to solve case study problems of realistic size is very moderate as can be seen from the numerical results reported in section 5 .

The notation used in the model formulation is given below.

\section{$\underline{\text { Indices, index sets }}$}

$\begin{array}{ll}i \in I & \text { sequence of production orders over all blocks; } i=1,2, \ldots, I \\ k \in K & \text { product types } \\ t \in T & \text { periods; } t=1,2, \ldots, T \text { (Note that } t \text { also indicates blocks, since one specific } \\ & \text { block is assigned to each period.) } \\ i(k, t) & \text { production order in which product } k \text { is produced in period (block) } t\end{array}$

\section{Parameters}

$B \quad$ setup time required before starting a block

$d_{k t} \quad$ demand element of product $k$ assigned to the end of period $t$

$h_{k} \quad$ costs per period for holding one unit of product $k$ in inventory

$L \quad$ length of a period

$M \quad$ sufficiently large number (i.e. the maximum size of a production order)

$S_{i} \quad$ setup costs for production order $i$

$\sigma_{i} \quad$ fixed processing time of production order $i$ (e.g. setup and clean-out time)

$\tau_{i} \quad$ variable processing time per unit of production order $i$

\section{$\underline{\text { Decision variables }}$}

$\begin{array}{ll}x_{i} & =1, \text { if production order } i \text { is produced ( } 0, \text { otherwise) } \\ y_{i} & \text { size of production order } i \\ t s_{i} & \text { start-off time of production order } i\left(t s_{1} \text { is given }\right) \\ P_{k t} & \text { stock of product } k \text { at the end of period } t\left(P_{k 0} \text { is given) }\right. \\ \delta_{i} & \text { duration of production order } i\end{array}$

The optimal production schedule can be determined by solving the MILP model presented below. This fundamental model formulation is based on the following assumptions.

- The total number of blocks is given in advance. Thus, major setup costs related to blocks do not need to be considered.

- The setup state of the production equipment can be preserved from period to period.

- The execution of a setup operation can be continued in the succeeding period.

- The pre-defined structure of the blocks is identical for each period.

- Each product type is produced only once per period (block). 
The objective is to minimize the sum of setup costs related to production orders and holding costs for carrying inventory of products from period to period.

$\min \sum_{i \in I} S_{i} \cdot x_{i}+\sum_{k \in K} \sum_{t \in T} h_{k} \cdot P_{k t}$

This cost function is minimized subject to the following constraints.

$$
y_{i} \leq M \cdot x_{i} \quad i \in I
$$

This constraint enforces the size of production order $i$ to zero if no corresponding setup operation is performed (i.e. $x_{i}=0$ ).

$$
\delta_{i}=\sigma_{i} \cdot x_{i}+\tau_{i} \cdot y_{i} \quad i \in I
$$

The duration of a production order consists of a fixed setup time and a variable quantitydependent processing time. (Note that $\delta_{i}=0$ if production order $i$ is not executed.)

$$
t s_{i} \geq t s_{i-1}+\delta_{i-1} \quad i=2, \ldots, I
$$

A production order is allowed to start as soon as the predecessor order has been completed. (Note that start-off times are also assigned to empty production orders. In this case, the startoff time of the successor order equals the start-off time of its predecessor.)

$$
t s_{t \cdot K}+\delta_{t \cdot K} \leq L \cdot t-B \quad t \in T
$$

According to the block planning concept, each block is assigned to a specific period and the final product $K$ in each block is known in advance. Constraint (5) ensures that each block is completed before the end of the corresponding period and that the major setup time is included in the execution time of each block. However, a block is allowed to start in an earlier period (and even be completed) provided that sufficient production capacity is available.

$$
P_{k t}=P_{k, t-1}+y_{i(k, t)}-d_{k t} \quad k \in K, t \in T
$$

For each product and period, the net change in inventory is determined by the quantity produced and the period demand of the final product. Note that $i(k, t)$ indicates the production order in which a specific product $k$ is produced in period (block) $t$.

Finally the domains of the decision variables are defined as follows.

$$
\begin{array}{lr}
x_{i} \in\{0,1\} & i \in I \\
y_{i} \geq 0 & i \in I \\
t s_{i} \geq 0 & i \in I \\
P_{k t} \geq 0 & k \in K, t \in T \\
\delta_{i} \geq 0 & i \in I
\end{array}
$$




\subsection{Extensions}

In many cases, specific issues arising from the individual application environment have to be considered. Some of these can easily be covered by simple extensions of the basic model formulation. Because of the large variety of application-specific issues we do not lay out in detail how these issues can be incorporated in the MILP model formulation.

- For instance, a number of heterogeneous blocks can be defined and binary decision variables can be introduced for the assignment of one of the pre-defined blocks to each period. In the case of yogurt production (see Lütke Entrup et al. 2005) blocks represent specific recipes upon which the production of a range of yogurt flavours is based.

- Operating conditions occasionally found in practice involve "all or nothing" production. i.e. production of a product type takes place during the entire shift or no product is produced at all.

- Another issue which can easily be accounted for is the use of parallel production or packaging lines.

- In the basic model formulation, demand elements are assigned to the end of a period, e.g. a week. In order to model deliveries during the period, e.g. at the end of a day, micro-periods have to be introduced and production orders have to be assigned to each individual micro-period. Still the property of block planning and production of a pre-defined order of product variants can be maintained.

- During peak periods it may not be feasible to satisfy all demand elements completely on time. Thus, additional decision variables can be used to reflect backorders or unfilled demand.

- Basic shelf life constraints can easily be considered by introducing additional variables for the assignment of production quantities to demand elements and defining the variables only for those production period - demand period assignments which do not violate the shelf life constraints. At the same time, inventory variables can be deleted from the model formulation. More rigid shelf life constraints require reformulations which are explained in Lütke Entrup et al. (2005) using a case study from fresh food production.

- Batch production is considerably important in the chemical industry. Defining production quantities as integer variables is a simple means to consider issues of discrete production quantities. Even production of batches on a series of chemical equipment units can easily be modelled as shown in Grunow et al. (2003).

Actually, some basic features of block planning are also reflected in the comprehensive supply network model suggested by Grunow et al. (2003) for application in the chemicalpharmaceutical industry. They show the practical applicability of a continuous time based model formulation for an industrial case study of extreme complexity and derive near-optimal solutions within reasonable computational time. In make-and-pack production, however, only a single production stage needs to be considered, thus, allowing optimal solutions almost in real time, an issue which is of considerable importance in an application environment, where rescheduling frequently takes place and quick response to changes in customer demand is required. 


\subsection{Alternative objective functions}

While economic objective functions can easily be defined at the supply network level of supply chain management, a variety of objectives is considered relevant at the detailed production planning and scheduling level. These objectives include:

- minimization of total costs for setups and inventory holding,

- minimization of makespan, i.e. the time after which the complete set of production orders is completed,

- produce as late as possible in order to minimize inventories,

- produce as early as possible in order to maximize the freshness of products,

- minimize unfilled demand,

- minimize operating costs of the production equipment,

- maximize profit of the products sold.

There is, however, no general overall objective function available which integrates all the above mentioned issues. Thus priorities and specific objective functions have to be defined depending on the respective application environment. For instance, in the fresh food industry, "produce as early as possible" is the preferred policy in order to increase the shelf-life of the products, while "produce as late as possible" can be seen as the dominating objective in the case of high-value products. In other industries, e.g. the production of specialty chemicals, minimizing the costs for setup and clean-outs as well as labour costs for operating the production equipment is often of utmost importance.

In the basic model formulation presented in section 3.1, minimization of setup and inventory holding costs was considered as the objective function. The major condition for the application of this objective is the definition of setup and inventory holding costs associated with the various production orders. Very often in practice, production managers face difficulties in defining these costs as out-of-pocket costs, since no clear relationship between cash flows and individual production orders can be identified. Instead, setup costs are seen as compensation for non-productive use of equipment and workforce, and inventory costs are introduced to penalize the build-up of stocks.

While minimizing total setup and inventory holding costs is regarded as the fundamental objective function in the academic literature on lot-sizing, a change of paradigm slightly takes place in practice caused by the increased importance of quick response to customer orders and the focus on the timely supply of goods within a supply network. Particularly, in the consumer goods industry, which is characterized by high and stable demand figures and short production throughput times, high utilization of bottleneck resources is often regarded as the key issue. Moreover, production is typically driven by short-term delivery requests so that inventories can merely be regarded as buffers between the manufacturing and the distribution stage of the supply chain. Accordingly, production managers in practice often consider minimization of the makespan, i.e. to complete the given production orders within the shortest possible time, as the appropriate objective function. The rationale behind this objective function is to save unproductive setup times and to provide increased flexibility for 
responding to changes in the size and timing of production orders from the downstream stages of the supply chain.

\section{SAP APO ${ }^{\odot}$}

The "Advanced Planner and Optimizer" software SAP APO ${ }^{\odot}$ represents one of the so-called Advanced Planning Systems (APS) which have gained considerable attention in many types of industry (cf. Günther 2005). APS are primarily concerned with supporting decision making activities in supply chain management at the strategic, tactical and operational decision level (cf. Stadtler and Kilger 2005). In contrast to classical MRP-systems, APS take into account the limited availability of resources and employ true optimization techniques. A variety of mathematical models and related algorithms are applied in APS to analyze and support production and logistics operations within the supply chain (see Günther and van Beek (2003) for applications in the process industries).

At present, a change of paradigm takes place from the classical MRP II philosophy, which is based on a strict top-down planning procedure not considering the limited capacity of the required resources, towards APS which utilize the significant progress that has been achieved in the development of optimization algorithms and modelling tools as well as the great advances in information technology. As a result, many industrial companies have strengthened their efforts to employ APS for solving different problems arising in the field of production and logistics.

Software packages to support and integrate activities along the supply chain are being offered by different software vendors, e.g. SAP, i2 technologies or People Soft (now belonging to Oracle), just to name the leading ones on the SCM software market. (For an overview of the architecture of these software packages see Meyr et al. 2005a). Despite the different orientation and industry focus of APS offered by the various software vendors, a common structure underlying most of the APS can be identified (cf. Meyr et al. 2005b). Figure 3 displays the typical software modules covering the different planning tasks.

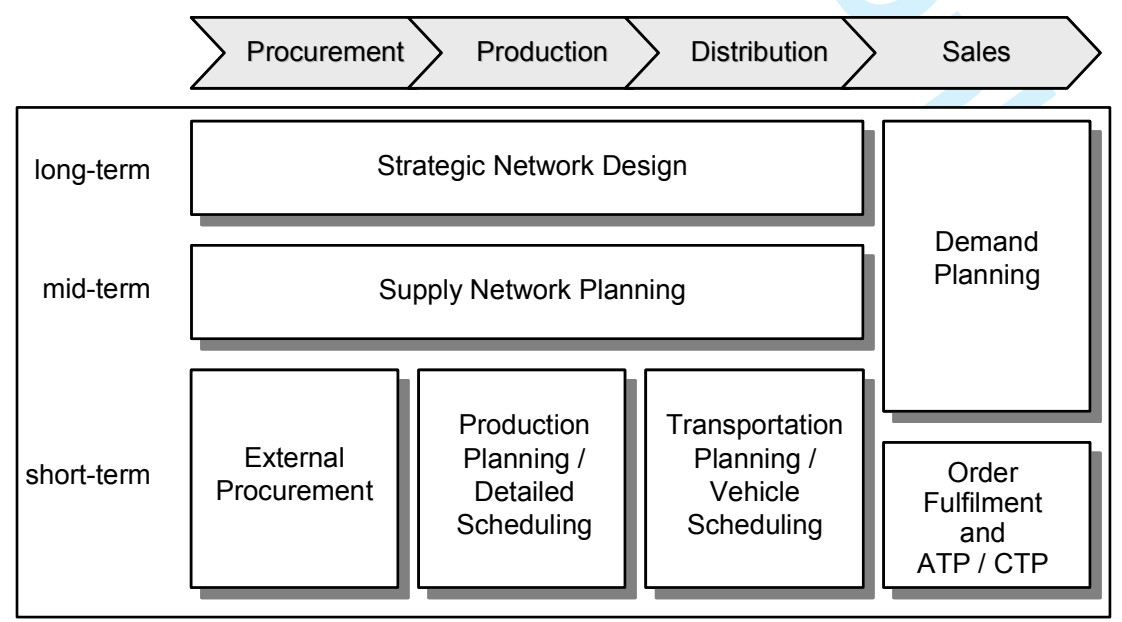

Figure 3: Software modules of advanced planning systems 
In APS the short-term level includes production planning and detailed scheduling (PP/DS) as the major module. The general goal of PP/DS is to generate production orders, which permit the timely fulfilment of customer orders. In APS the PP/DS task is usually carried out according to a finite scheduling policy, i.e. the limited availability of resources is taken into account. Specifically, the detailed sequencing and time-phasing of production orders at all of the affected resources have to be determined.

To support PP/DS in specific application environments, a number of dedicated tools have been integrated into the corresponding module of SAP APO ${ }^{\odot}$. Among these tools „characteristic-dependent planning” is specially designed for application in industries which produce variants of a basic product type with different properties (e.g. colour, grade, coating, and other physical or chemical specifications). Characteristic-dependent planning applies the concept of block planning, which schedules a class of products with similar specifications in a joint production run. However, characteristic-dependent planning in SAP APO ${ }^{\odot}$ does not represent a model-based optimization approach, but a tool which provides support for the human planner who carries out the planning procedure. Such a planning procedure typically consists of the following steps.

- Before starting the planning run, so-called production-process-models (PPMs) have to be defined as master data. APS use PPMs in order to document how a product is produced from input materials and processed through a sequence of activities. PPMs provide a combined representation which defines both, the detailed machine routing with the resource consumption per item and the bill of material (BOM) information of each product. A typical PPM is structured as follows. At the highest level, operations define the manufacturing stages as well as inspection and transportation actions. For each operation, the sequence of individual activities associated with the operation is given. Activities not only include manufacturing steps, but also set-up or cleaning of equipment units. Finally, for each activity, the required resources (e.g. equipment, personnel, tools, storage devices) and material inputs are defined. Relevant data, e.g. unit production times or bill-of-material coefficients, are attached to the appropriate objects in the PPM. Moreover, weights can be assigned to the arcs, which link the activities, indicating the required minimum or maximum time lag between activities. To model alternative resources and routings, different modes can be defined for selected activities.

- The PP/DS module allows the planner to define classes of product characteristics. In the example of figure 4 the different variants of the final product $F P$ result from the characteristics which are assigned to its components $C_{1} \ldots C_{6}$. First the classes of product characteristics are determined which reflect issues relevant for the formation of setup families and the generation of schedules which exploit the similarity between product variants. Each class of product characteristics comprises a number of attributes to which the product variants are assigned. For instance, class $A_{1}$ in figure 4 might represent the required machine setup (processing mode, material mix, production rate, etc.). The second class $A_{2}$ could represent specific packaging materials which are used for the production of different product variants. The main advantage gained at this step is the reduced volume of master data. 


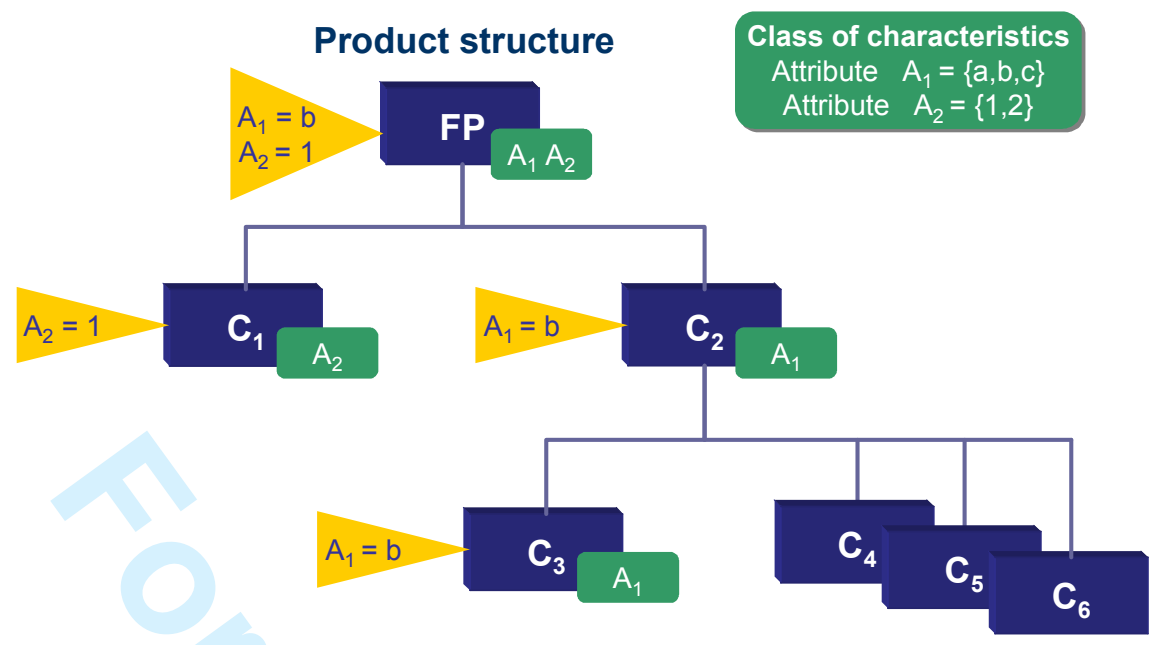

Figure 4: Representation of product characteristics in $S A P A P O^{\odot}$

- The block planning procedure itself provided by SAP APO ${ }^{\circ}$ is fairly simple. For each production period (e.g. a week) the planner identifies a major characteristic, for instance, a certain machine setup. As a result, only those production orders showing the respective characteristic (e.g. products belonging to the corresponding setup family) are assigned to the particular production period. This assignment is carried out by a heuristic procedure, which is not accessible to the planner. Obviously, no specific objective function, e.g. minimizing holding and setup costs, is considered. Moreover, the generation of production orders, i.e. optimizing the size of the corresponding lot sizes with respect to some cost function and taking capacity constraints into consideration, is not supported.

- Finally, the sequence of the production orders can be optimized by use of a genetic algorithm or by constraint programming techniques. In this step, minimization of makespan or minimization of setup times or a combination of both is considered as objective function.

In contrast to the MILP model approach presented in the previous section, the characteristicdependent planning tool of SAP $\mathrm{APO}^{\odot}$ aims at supporting the human planner in practice by generating schedules according to a rigid block planning principle. Thus both approaches are not directly comparable in terms of mathematical solution quality. However, major benefits could be gained in practice by employing $\mathrm{SAP} \mathrm{APO}^{\odot}$ as a powerful planning tool and at the same time by making use of advanced optimization techniques, which are already integrated into the supply network planning model of SAP APO ${ }^{\odot}$. This way both approaches may complement each other.

\section{Case Study}

In order to demonstrate the practical applicability of the proposed block planning concept, we consider the production system of a major producer of hair dyes as a case study. The actual dye is offered in 26 colour variations. Sales units consist of three components: the dye cream, the dispersion, and the shampoo, which are packed together in a box (see figure 5). 
The production system for hair dyes consists of four processing lines, an intermediate storage area, and five filling and packaging lines (see figure 6). A typical processing line comprises a premix measuring station and a blender, which operates in batch mode. Three processing lines are used to produce dye cream and dispersion. Shampoo is produced on a separate line. Each processing line is capable of processing a variety of products. After completion of the processing stage, material is transferred to the intermediate storage area, where also quality control takes place. Next, intermediate products are transferred to the packaging lines. Of the five lines available, two are dedicated to the bottling of shampoo. On the other three lines, the dye cream and the dispersion are bottled and, finally, packed together with the shampoo into boxes for shipment to customers.

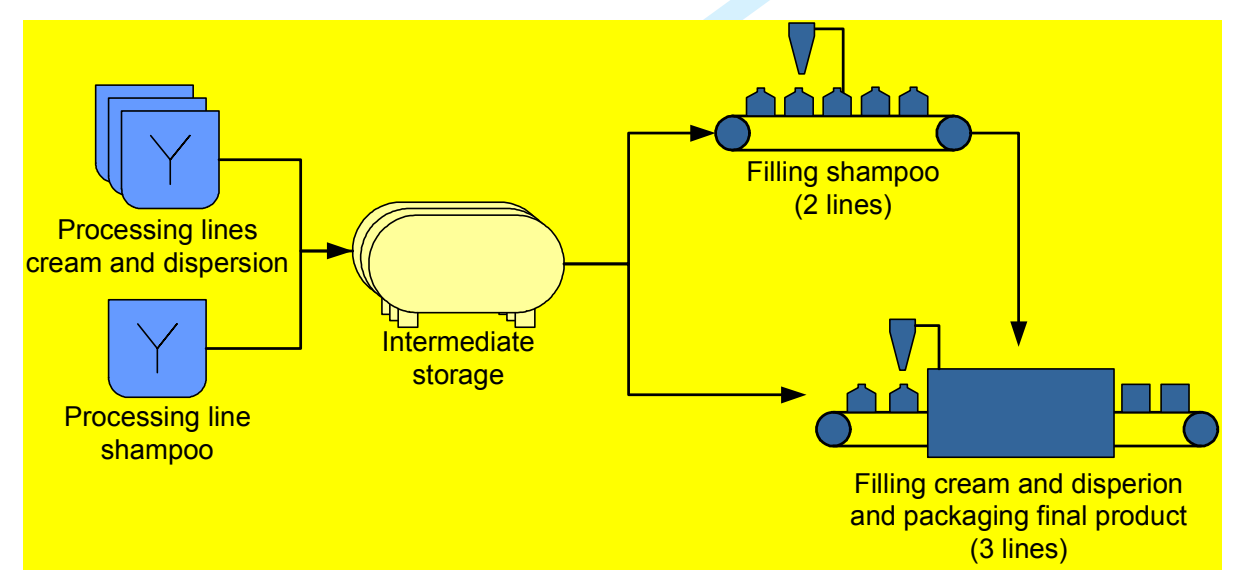

Figure 6: Production system for hair production

Both the processing and packaging lines must be cleaned when switching between two different product variants. The changeover times are highly sequence dependent. For instance, intensive cleaning is required when switching from a very dark to a very light-coloured product. However, only minor cleaning is necessary for changing over to a similar product. To support production planning, products are assigned to four setup families based on their colour characteristics. For each setup family, a natural production sequence exists, which 
minimizes changeover time. As a consequence, products are always produced in the given order within the family. Hence, major setups are only necessary when switching between families. Also for the setup families a sequence is defined which minimizes changeover times. As a result, a complete production cycle is obtained which is composed of the pre-defined sequence of families and products within each family. In the industrial application considered, the length the production cycle was set to four weeks. In order to simplify the plant operation and in particular to consolidate the setup activities, management has decided to produce only one type of product at any point in time. During the time span assigned to a product, all material routings are fixed and the processing and packaging lines on which a production order will be processed are known in advance.

Due to its typical make-and-pack characteristics, the production of hair dyes represents an ideal application scenario for the proposed block planning concept. In this application, each production cycle comprises a four-week period. Owing to the limited capacity of the blenders, a production order of a particular product may be split into a number of batches. Hence, the duration of a campaign consists of a fixed changeover time and a variable processing time, which depends on the number of batches to be produced. Since the product routings between the various equipment units are fixed, the production process can be easily aggregated as described in the previous section.

In our case study investigation, real world data provided by the hair dye manufacturer were used. Table 1 indicates some major features of the resulting MILP model. It can be seen from table 1 that the optimal solution to the case study problem was achieved within less than one second of CPU time. The block planning model was implemented using ILOG's OPL Studio as a modelling environment and the standard optimization software CPLEX 7.0 as solver.

Table 1: Features of the MILP model for the case study application

\begin{tabular}{cc}
\hline No. of products & 26 \\
No. of production orders & 156 \\
No. of periods & 6 \\
No. of variables & 780 \\
No. of constrains & 786 \\
CPU time (seconds) & 0.25 \\
\hline
\end{tabular}

As far as the $\mathrm{SAP} \mathrm{APO}^{\odot} 3.1$ implementation is concerned, no direct comparison can be made, since the characteristic-dependent planning does not comprise a comprehensive optimization model. Yet a considerable reduction in planning effort is achieved due to a significant compression of the volume of the required master data (see table 2). 
Table 2: Effect of characteristic-dependent planning on master data volume

\begin{tabular}{lcc}
\hline \multirow{2}{*}{\multicolumn{1}{c}{ Master data }} & \multicolumn{2}{c}{ No. of required master data records } \\
\cline { 2 - 3 } & $\begin{array}{c}\text { Characteristic-dependent } \\
\text { planning }\end{array}$ & $\begin{array}{c}\text { Conventional } \\
\text { planning }\end{array}$ \\
\hline Production-process-models & 30 & 56 \\
Resources & 14 & 14 \\
Products & 37 & 140 \\
\hline Total & 84 & 213 \\
\hline
\end{tabular}

\section{Conclusions}

For realizing block planning concepts in the consumer goods industry, two different approaches have been presented. One is taken from SAP APO ${ }^{\odot}$ which represents a powerful Advanced Planning System. In particular, the feature of characteristics-dependent planning provided by the Production Planning / Detailed Scheduling (PP/DS) module of SAP APO ${ }^{\odot}$ 3.1 has been used. It could be shown that the SAP APO ${ }^{\odot}$ software is well suited to support block planning for make-and-pack production systems. This approach, however, can be enhanced by an MILP-based block planning concept presented by the authors. In contrast to the academic literature on lot-sizing and campaign planning, the corresponding model formulation is based on a continuous representation of time. Thus the number of variables and constraints is considerably reduced. As a result, the proposed MILP approach shows a remarkable computational efficiency, when applied to real world problems.

In order to illustrate the practical applicability of the block planning concept the production of hair dyes was considered as a case study. It could be shown that both, the APS approach and the MILP modelling approach, are well suited to the needs of a make-and-pack production system. Future research will be devoted to enhance the proposed planning concept to more complex production systems to be found in the chemical industry. A current research project deals with campaign planning in multi-level supply networks and the coordination of production schedules at different production sites. As a basis for this integrated planning approach, an MILP modelling framework similar to the proposed block planning approach is employed.

\section{References}

Blömer, F., Günther, H.-O., Scheduling of multi-product batch processes in the chemical industry, Computers in Industry, 1998, 36, 245-259.

Blömer, F., Günther, H.-O., LP-based heuristics for scheduling chemical batch processes, International Journal of production Research, 2000, 38, 1029-1051.

Chopra, S., Meindl, P. Supply chain management: Strategy, planning, and operation, $2^{\text {nd }}$ ed 2004 (Prentice Hall, Upper Saddle River, N.J.). 
Cooke, D. L., Rohleder, T. R., Silver, E. A., Finding effective schedules for the economic lot scheduling problem: A simple mixed integer programming approach, International Journal of Production Research, 2004, 42, 21-36.

Dennis, D, Meredith, J., An empirical analysis of process industry transformation systems, Management Science, 2000, 46, 1085-1099.

Elmaghraby, S. E., The Economic Lot Scheduling Problem: Review and Extensions, Management Science, 1978, 24, 587-598.

Floudas, C.A., Lin, X., Continuous-time versus discrete-time approaches for scheduling of chemical processes: a review, Computers and Chemical Engineering, 2004, 28, 2109-2129.

Grunow, M., Günther, H.-O., Lehmann, M., Campaign planning for multi-stage batch processes in the chemical industry, OR Spectrum, 2002, 24, 281-314.

Grunow, M., Günther, H.-O., Yang, G., Plant coordination in pharmaceutics supply networks, OR Spectrum, 2003, 25, 109-141.

Günther, H.-O., Supply Chain Management and Advanced Planning Systems: A Tutorial. In Supply Chain Management und Logistik, edited by H.-O. Günther, D. Mattfeld, L. Suhl pp. 3-40, 2005 (Physica: Heidelberg).

Günther, H.-O., van Beek P. (Eds.), Advanced Planning and Scheduling Solutions in Process Industry, 2003, (Springer: Berlin).

Honkomp, S.J., Lombardo, S., Rosen, O., Pekny, J.F. The course of reality - why process scheduling optimization problems are difficult in practice, Computers and Chemical Engineering, 2000, 24, 323-328.

Lütke Entrup, M., Günther, H.-O., van Beek, P., Grunow, M., Seiler, T., MILP approaches to shelf life integrated planning and scheduling in yogurt production, International Journal of Production Research, 2005, 43, 5071-5100.

Mendez, C.A., Cerda, J., An MILP-based approach to the short-term scheduling of make-and-pack continuous production plants, OR Spectrum, 2002, 24, 403-429.

Meyr, H., Rohde, J., Wagner, M., Wetterauer, U., Architecture of selected APS. In: Supply chain management and advanced planning, edited by $\mathrm{H}$. Stadtler and C. Kilger, pp. 341-353, $3^{\text {rd }}$ ed. 2005a (Springer: Berlin.)

Meyr, H., Wagner, M., Rohde, J., Structure of advanced planning systems. In: Supply chain management and advanced planning, edited by $\mathrm{H}$. Stadtler and C. Kilger, pp. 109-115, $3^{\text {rd }}$ ed. 2005b (Springer: Berlin.)

Soman, C.A., van Donk, D.P., Gaalman, G., Combined make-to-order and and make-to-stock in a food production system, International Journal of Production Economics, 2004, 90, 223-235.

Stadtler, H., Kilger, C. (Eds.), Supply chain management and advanced planning, $3^{\text {rd }}$ ed. 2005, (Springer: Berlin).

van Dam, P., Gaalman, G.J.C., Sierksma, G., Designing scheduling system for packaging in process industries: A tobacco company case International Journal of Production Economics, 1998, 56, 649-659.

van Sonsbeek, J.T.M., van Beek, P., Urlings, H.A.P., Bijker, P.G.H., Hagelaar, J.F.L., Mixed integer programming for strategic decision support in the slaughter byproduct chain, OR Spektrum, 1997, 19, 159-168. 